\title{
INNOVATIONS
}

\section{Humor and creativity}

\author{
By Norman D. Stevens \\ Director \\ The Molesworth Institute
}

In "Creativity, Innovation and Risk-Taking," C $\nleftarrow R L$ News, July/August 1987, Joanne R. Euster, as ACRL president-elect, raised the question of "how bureaucratic, highly structured organizations...can encourage creative thinking and innovative behavior" (p.405). She suggested that creativity can be taught, that innovation can be developed systematically, and offered some ideas and suggestions. One important element that she failed to mention, and that is too often overlooked, is the use of humor in the promotion and development of creativity and innovation. While the development of a true sense of humor is not something that can be taught, or perhaps even encouraged, the use of humor, even in serious settings, can be encouraged and supported as a technique that will help foster the maximum degree of creativity and innovation.

One's innate sense of humor can be applied in a variety of ways in the operation and management of libraries to help us avoid becoming stale and to take a fresh look at what we are doing and why. There are some practical observations and suggestions about how humor can be used effectively to promote a fresh approach to our work.

One significant use of humor is in the initial steps of challenging existing policies, procedures, and practices that may have become outmoded and arcane and that, indeed, may always have been less than satisfactory. By, for example, carrying out the application of a policy or a procedure to an extreme, it is often possible to demonstrate the true inappropriateness of that policy or procedure and the extent to which it is simply a standard bureaucratic response. Seeing and laughing at the folly of our ways can break down our attachment to the old and can bring about creative change.

Humor can also be helpful in stretching our imagination as we consider new policies, procedures, and programs. The use of "blue-sky" and "what if" techniques are now routinely encouraged as a way of developing a laundry list of potential approaches to a situation in a way that will foster the broadest possible examination of all options. Those techniques should allow and encourage the inclusion of the most outrageous nonsensical solutions and suggestions. By accepting suggestions that are so far out as to be unquestionably unacceptable, one points out how impractical the existing situation may be, and how little modest changes will accomplish, while also avoiding placing practical, but radical, suggestions that may be worth serious consideration all alone at the outer end of the spectrum. Having wildly outrageous suggestions to eliminate from consideration may well save somewhat less outrageous suggestions from being dismissed without an adequate hearing. Extreme suggestions may also encourage those who make them, and others, to stretch their imagination to come up with creative and innovative ideas that are realistic. In some cases the presentation of a truly creative idea, or at least the germ of that creative idea, in a humorous fashion may make it appear less threatening and more acceptable. A good idea can appear, at first, to be simply a joke but, as its humorous aspects are peeled away, the kernel of truth and the idea's practicality may be revealed and understood.

Many internal library meetings and discussions are of a highly serious nature that take place in an uncertain atmosphere. Apprehension, hostility, and tension are not conducive to creative thinking and innovation. When those elements are present (or even dominate as they all too often do) a discussion of a library issue, the response of the participants as they seek to solve a problem is likely to be 
caution and timidity. Reliance on existing policies and practices ("we've always done it this way"), strict interpretation of rules and regulations ("it says that students may not borrow reference books for use outside the library"), shifting the blame ("I would have been able to help that user if books were cataloged in a timely fashion"), and similar techniques designed, on the one hand, to avoid responsibility or even blame and to avoid, on the other hand, leadership and the promotion of reform are likely to prevail. The careful and appropriate use of humor, not to punish or poke fun at an individual or a unit, to point up the futility of a situation, how ridiculous a particular procedure seems in retrospect, or the folly of existing policies and practices can, by breaking the ice, go a long way towards creating a climate in which creative and innovative ideas have a better chance of being put forward and given serious consideration.

Humor can also be extremely effective in creating a bond among those who are working on an assignment in a way that few other techniques can. Activities that bring individuals together over time invariably create "in jokes" that are understood only by those involved and make no sense even to other colleagues. That kind of bond, which should be encouraged, creates an atmosphere in which new ideas are more likely to flourish as the group finds an identity that brings it together as a group not as a collection of individuals each with something to risk or lose.

Libraries need to be careful to nurture and support, and not punish or ridicule, those few members of the staff who are willing to take on a permanent unpaid assignment as gad-fly. The constant prodding of the library bureaucracy through the use of humor and satire is needed to keep that bureaucracy from becoming too firmly entrenched.

Regular reminders of our foolish ways need to be encouraged. The skills needed by a gad-fly are not ones that can be listed in a job description, assigned to a particular position, or identified as we inter-

\section{Feeling funny?}

Norman D. Stevens, as director of the Molesworth Institute, has an abiding interest in collecting as well as creating library humor. He would welcome examples of academic library humor, particularly in the form of pieces in internal academic library newsletters for his collection. Dr. Stevens has agreed to sample such items as they are received and, from time to time as the quality warrants, to prepare a brief column of excerpts of the best academic (or research) library humor for College of Research Libraries News. Material can be sent to him at 143 Hanks Hill Road, Storrs, CT 06268. Please also enclose your business card (signed and dated on the verso) to enhance Dr. Stevens's collection of library ephemera. view and hire staff. They are probably innate skills not found in most staff but they are skills to be fostered, or at least tolerated, in those who do have them.

Apart from its appropriate use in formal settings where it can help foster a creative climate, the continuing use of humor in internal library newsletters, occasional nonsensical memos, notices and signs, and even, from time to time, within formal memos and presentations offers an opportunity for the organization as a whole to be seen by its members as one in which the rigid bureaucratic structure in which we work is just that. Those uses reveal the fact that the library is not necessarily the ideal setting that we would like it to be. The constant reinforcement of the notion and power of the library as a bureaucracy through always stiff and formal newsletters, memos, and presentations is to be avoided at all costs. If the overall structure is seen simply as just another entrenched bureaucracy, even the sporadic use of humor in dealing with particular problems and issues can do little to save the day.

Laughing together is an ideal way to foster an atmosphere in which creativity and innovation, and even risk-taking, may stand a chance of emerging, surviving, and perhaps flourishing.

\section{The Future of BI}

ACRL's Bibliographic Instruction Section will hold a one-day Preconference program in New Orleans on July 8,1988 . The program is entitled, "The Future of BI: Approaches in the Electronic Age," and will feature two keynote speakers: Sharon Hogan, director of libraries at Louisiana State University, and Christine Borgman, associate professor at the University of California, Los Angeles.

In the afternoon participants will have the opportunity to attend four break-out sessions and choose from eight topics:

- Deborah Murphy, University of California, Santa Cruz, and creator of BiblioMania, will lead a session on developing desktop CAI;

- Claudette Hagle, University of Dallas, will address the one-shot lecture;

- choosing and using appropriate technology will be the focus of a session led by Pauline Rankin, Louisiana State University;

-Sarah Watstein, Hunter College, will present a session on burnout in BI librarians;

-Sandra Ready, Mankato State University, will lead a session on teaching the online catalog;

- Jane Kleiner, head of reference at Louisiana State University, will focus on teaching the enduser to search databases;

- Alan W. Ritch, University of California, 
Santa Cruz, will lead a session on electronic pointof-use instruction;

- and Mignon Adams, Philadelphia College of Pharmacy and Sciences, will address evaluating the instructor.
Registration details will be published in a future issue of C $\& R L$ News. The chair of ACRL's BIS Preconference Committee is Jane Kleiner, Louisiana State University.

\section{Perfect preservation: A lesson from the past?}

\author{
By Philip H. Young \\ Library Director \\ University of Indianapolis
}

The library profession is leading the way in identifying an impending crisis which threatens the very roots of modern culture-I refer to the acidic destruction of books. For the last century, the paper used in books, magazines, and newspapers was made with acids which are now causing it to become brittle and to crumble into dust, bearing with it society's recorded knowledge of the last several generations.

Librarians are attempting to avert the cultural suicide of our era by preserving their library collections with the assistance of high technology. Deacidification programs are underway, as are microfilming projects to photograph key items in research collections. Even newer technologies promise other methods of saving the written record of the 20th century, including digitizing it for electronic storage in traditional, magnetic formats or using the new optical wizardry of CD-ROM.

Unfortunately these efforts, though wellintentioned, have proven costly, slow and (worst of all) not really permanent. A deacidified book will still face the mechanical rigors of usage, including dog-eared pages and accidental drops into mudpuddles during a rush to catch a bus. Microfilm, microfiche, and other photographic processes will greatly extend the print's life but are themselves vulnerable to chemical decay of image and file with the eventual loss of viability. Electronic media are also susceptible to long-term decay, as well as to short-term damage. (Who hasn't heard of someone accidentally typing DEL ${ }^{*} \cdot{ }^{*}$ on their computer keyboard?) No one seems to know what the shelf-life of CD-ROM will be, but it is already apparent that surface scratches interfere with image-processing.

Is our effort to preserve the records of our age in vain? Is there no incorruptible medium to which to entrust the essence of our era? Perhaps examining the methods used in earlier ages might provide an insight for us. Since antiquity, writers have used parchment, vellum and other skins, and non-acidic paper for preservation of their musings, but these media, while stable when stored in a monastery or public archives, do not guarantee a lasting record. In ancient times records were also written on bronze, wood and stone. Although wood is clearly impermanent, metal and stone present the desired characteristics of virtual indestructibility. We can read a 6 th-century B.C. treaty of the Greek city Sybaris written on a bronze plate or any of the thousands of imperial Roman tomb inscriptions carved into stone (and now cluttering the world's museums) just as well as at the time of their creation. The written record has been preserved! Unfortunately, however, metal and stone are not inexpensive, easily obtained, rapidly inscribed, or efficiently stored in quantity. Who would want to chisel War and Peace into blocks of marble (or store the result in their library!)?

Happily, research tells us that there is yet another medium used for writing by ancient civilizations which overcomes these problems - the clay tablet. Humanity's earliest surviving documents were imprinted in soft clay, baked to rock-like hardness, and stored for systematic recall (or, as often happened, for posterity.) Do clay tablets meet our needs for writing permanence? They do, indeed, approach indestructibility. Granted, if you drop one, it breaks - but the text is not lost because any archaeologist worth his or her salt can piece it back together, good as new. (Try that with acid paper!) Furthermore, clay is easily and quickly inscribed, unlike metal or stone. It can be found almost anywhere and molded into manageable units for efficient handling and storage. And, most importantly, the writing lasts forever!

My fellow librarians, I submit to you that our preservation efforts have been misdirected. Instead of expensive deacidification, microphotography, electronic or optical conversion, we should be transcribing our hallowed texts onto clay tablets!

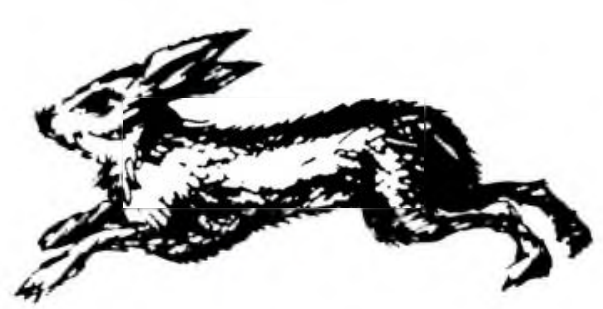

March 1988 / 147 